\title{
Impact of Health Human Resources on the Output Efficiency of Residents' Health Status in China
}

Jingjing Cheng ( $\square$ evercjjee@126.com )

School of business administration, Northeastern University https://orcid.org/0000-0002-9916-494X

Xianming Kuang

Center for Economic Research, China Institute for Reform and Development

Linghuang Zeng

Human Resources Department, The First Affiliated Hospital of Hainan Medical University

Research

Keywords: Human resources for health (HRH), residents' health status, data envelopment analysis (DEA), Tobit regression

Posted Date: July 17th, 2020

DOI: https://doi.org/10.21203/rs.3.rs-41971/v1

License: (c) (i) This work is licensed under a Creative Commons Attribution 4.0 International License.

Read Full License 


\title{
Impact of Health Human Resources on the Output Efficiency of Residents' Health Status in China
}

Jingjing Cheng ${ }^{1, *}$, Xianming Kuang ${ }^{2}$ and Linghuang Zeng ${ }^{3}$

${ }^{1}$ School of Business Administration, Northeastern University, Shenyang 110819, China; evercjjee@126.com

${ }^{2}$ Center for Economic Research, China Institute for Reform and Development, Haikou 570311, China; 13907572403@163.com

${ }^{3}$ Human Resources Department, The First Affiliated Hospital of Hainan Medical University, Haikou 570102, China; m18889324175@126.com

*Author to whom correspondence should be addressed.

\begin{abstract}
Background: Along with the development of the Chinese economy, there has been an increasing demand for resident health care services. Human resources for health (HRH) are a cornerstone in the medical system and have a significant influence on the health status of residents.
\end{abstract}

Methods: This study employed the data envelopment analysis (DEA) to explore the output efficiency of residents' health status. The input variable was medical services and the output variable was the health status of residents. We examined aspects of the provincial and national dimensions in China and used a Tobit regression analysis to explore the impact of HRH on output efficiency scores.

Results: We found that in the provincial dimension, all kinds of HRH (except for technicians) had a significantly positive impact on the output efficiency of residents' health status. In the national dimension, licensed (assistant) doctors, registered nurses, and village doctors had a significantly positive effect on the efficiency in the "with 
surgical procedures" model. In the "without surgical procedures" model, the effect factors changed to registered nurses and pharmacists. Most importantly, pharmacists played a critical role in both the provincial and national output efficiency scores. For pharmacists, the influence coefficient was three times higher than licensed (assistant) doctors and 11 times higher than registered nurses.

Conclusions: There is asymmetry between the demand for drug therapy and the lack of clinical pharmacists. Optimizing the allocation of HRH should be a top priority for healthcare systems and the government should adopt a long-term perspective.

Keywords: Human resources for health (HRH); residents' health status; data envelopment analysis (DEA); Tobit regression

\section{Introduction}

Along with the development of the Chinese economy, there has been an increasing demand for resident health care services. In 2016, China proposed the strategic theme of "healthy China" and issued a notice on key tasks that could enhance reform in the medical system by 2019. A guiding ideology in this movement is to "transform the focus from curing diseases to people's health". Human resources for health (HRH) are capable of providing basic medical services and are essential for continuous improvement of residents' health status. Moreover, HRH ensure social stability and economic development.

It is important to analyze the impact of $\mathrm{HRH}$ on the output efficiency of residents' health status so that the government can modify health policy to improve the overall efficiency of medical services and residents' health status. This study employed the data envelopment analysis (DEA) to explore the output efficiency of residents' health status. The input variable was medical services and the output variable was the health status of residents. We examined aspects of the provincial and national dimensions in China and used a Tobit regression analysis to explore the impact of the HRH on output efficiency scores. 
The remainder of this paper is organized as follows. Section 2 is the literature review. Section 3 details the materials and methods. Section 4 presents the empirical study. Section 5 is the discussion. Section 6 offers conclusions and policy recommendations.

\section{Literature Review}

HRH are a cornerstone of the medical system. Although many researchers have indicated that $\mathrm{HRH}$ availability has improved in some countries, out-of-balance, insufficient, and limited HRH availability persists in many other countries. Therefore, many countries still need to develop a long-term HRH plan ${ }^{[1-8]}$. Narasimhan $(2004)^{[9]}$ claimed that the quantity and distribution of HRH directly influence the quality of medical services and the long-term development of the medical system. Furthermore, $\mathrm{HRH}$ are the main force involved in dealing with public health emergencies. Fraher $(2020)^{[10]}$ argued that HRH are responsible for how well a country responds to and handles the COVID-19 crisis. Pharmacists have been deemed the health professional nearest to residents and therefore particularly qualified to provide convenient and efficient medical care for everyday diseases [11-13]. Ung (2020) ${ }^{[14]}$ stated that pharmacists have made a great contribution to community health during the COVID19 outbreak.

Health economists have put forward a theory to welfare economics that argues health maximization is a resource allocation goal ${ }^{[15-16]}$. Medical service equity is a key factor for social fairness, but service delivery and health resource allocation in China is still inefficient ${ }^{[17-19]}$. Meng (2019) ${ }^{[20]}$ proposed that health resources in China are inefficient because healthcare is overused and health resource distribution is uneven. $\mathrm{Fu}$ (2018) [21] suggested that the Chinese government focus on optimizing and allocating need-based health resources. Chowdhury $(2014)^{[22]}$ noted that countries with inadequate health resources need to focus on health service efficiency and hospital resource productivity. Tomblin (2013) ${ }^{[23]}$ posited that health care planning becomes 
difficult and unpredictable when resources are constrained and new health conditions surge (i.e., the COVID-19 pandemic).

Many studies have employed the DEA and used the Tobit regression analysis to evaluate health care efficiency and analyze influential factors. Domestic scholars have studied the regional efficiency differences in China's medical system ${ }^{[24-27]}$. Other scholars have compared efficiency scores before and after Chinese healthcare reform ${ }^{[28-30]}$. Foreign scholars have also widely researched efficiency and its contributing factors in the medical system ${ }^{[31-36]}$. A number of studies have shown that DEA approaches are widely used to assess healthcare system efficiency. Table 1 briefly summarizes the input and output variables developed in previous empirical studies that monitored efficiency.

Table 1. Input and output variables used in previous studies.

\begin{tabular}{|c|c|c|}
\hline Authors & Inputs & Outputs \\
\hline Cheng $[28]$ & Labor and capital & $\begin{array}{l}\text { Number of outpatients, emergency } \\
\text { visits, and inpatients }\end{array}$ \\
\hline Hamidi [37] & $\begin{array}{c}\text { Number of beds, doctors, nurses, and } \\
\text { non-medical staff }\end{array}$ & $\begin{array}{l}\text { Number of treated inpatients and } \\
\text { outpatients }\end{array}$ \\
\hline Lee et al. ${ }^{[38]}$ & Number of beds, doctors, and nurses & $\begin{array}{c}\text { Number of inpatient and outpatient } \\
\text { visits }\end{array}$ \\
\hline Afonso ${ }^{[39]}$ & $\begin{array}{l}\text { Physicians, nurses, acute care beds, and } \\
\text { MRI }\end{array}$ & $\begin{array}{l}\text { Life expectancy, infant mortality, and } \\
\text { potential years of life lost }\end{array}$ \\
\hline Chen ${ }^{[40]}$ & Number of physicians, nurses, and beds & $\begin{array}{l}\text { Number of outpatient visits and } \\
\text { inpatient cases }\end{array}$ \\
\hline $\mathrm{Hu}^{[27] 2727}$ & $\begin{array}{c}\text { Number of doctors, medical } \\
\text { technicians, other personnel, hospital } \\
\text { beds, and fixed assets }\end{array}$ & $\begin{array}{c}\text { Number of outpatient and emergency } \\
\text { room visits, inpatient days, and patient } \\
\text { mortality }\end{array}$ \\
\hline
\end{tabular}




\begin{tabular}{|c|c|c|}
\hline Asandului [41] & $\begin{array}{l}\text { Number of doctors, hospital beds, and } \\
\text { public health expenditures as } \\
\text { percentage of gross domestic product } \\
\text { (GDP) }\end{array}$ & $\begin{array}{l}\text { Life expectancy at birth, health } \\
\text { adjusted life expectancy, and infant } \\
\text { mortality rate }\end{array}$ \\
\hline Yang ${ }^{[42]}$ & Population into three groups by year & $\begin{array}{c}\text { Physicians, hospital beds, and medical } \\
\text { expenditures }\end{array}$ \\
\hline $\mathrm{Ng}{ }^{[43]}$ & $\begin{array}{c}\text { Number of doctors, nurses, } \\
\text { pharmacists, other staff, and beds }\end{array}$ & $\begin{array}{c}\text { Number of outpatient and inpatient } \\
\text { cases }\end{array}$ \\
\hline Kontodimopoulos & Number of doctors, nurses, and beds & $\begin{array}{l}\text { Outpatient visits, admissions, and } \\
\text { preventive medical services }\end{array}$ \\
\hline
\end{tabular}

Although an increasing number of studies are analyzing health care efficiency, very few studies have investigated the output efficiency of residents' health status or identified HRH as impact factors for medical efficiency in China. Understanding the impact HRH have on residents' health status and output efficiency is particularly topical for health policy makers, and therefore more empirical studies are needed.

\section{Materials and Methods}

\subsection{Network DEA Methodology}

In this study, the DEA was used to explore the output efficiency of residents' health status. The DEA was first proposed in 1978 by Charnes and Cooper [45], two famous American operational research experts, and has great advantages in dealing with multiple input and output problems.

In Model (1), there are $n$ decision making units (DMUs), each of which uses $m$ inputs to produce $s$ outputs. $D M U_{j}(j=1,2, \ldots, n)$ represents the $j$ th $\mathrm{DMU}$, where $x_{j}=\left(x_{1 j}, x_{2 j}, \ldots, x_{m j}\right)^{T}$ are the inputs and $y_{j}=\left(y_{1 j}, y_{2 j}, \ldots, y_{s j}\right)^{T}$ are the outputs for each DMU. Moreover, $v=\left(v_{1}, v_{2}, \ldots, v_{m}\right)^{T}$ is the weight of the input and $u=\left(u_{1}, u_{2}, \ldots, u_{s}\right)^{T}$ is the weight of the output. At the same time, $v \in E^{m}, u \in E^{s}$ makes the efficiency evaluation index of $D M U_{j}$ : 


$$
\theta_{j}=\frac{u^{T} Y_{j}}{v^{T} X_{j}}=\frac{\sum_{r=1}^{s} u_{r} y_{r j}}{\sum_{i=1}^{m} v_{i} x_{i j}},(j=1,2, \ldots, n)
$$

According to the basic ratio-based DEA model, we can always pick the right weight vector to make $\theta_{j} \leq 1$. Assuming that $D M U_{o}(o \in\{1,2, \ldots, n\})$ is not optimal in these $n$ decision units, we find the right $u$ and $v$ to maximize $\theta_{o}$. This particular DMU performance can be measured by the classic CCR (Charnes, Cooper, and Rhodes, 1978) programming model:

$$
\begin{array}{ll}
\text { Maximize } & \frac{\sum_{r=1}^{s} u_{r} y_{r o}}{\sum_{i=1}^{m} v_{i} x_{i o}}=\theta_{o} \\
\text { subject to } & \frac{\sum_{r=1}^{s} u_{r} y_{r j}}{\sum_{i=1}^{m} v_{i} x_{i j}} \leq 1, j=1,2, \ldots, n \\
& \mathrm{u}_{\mathrm{r}}, v_{i} \geq 0, \forall r, i .
\end{array}
$$

It is difficult to calculate an optimal solution in Model (2), so conversion to a linear form using the Charnes-Cooper ${ }^{[46]}$ transformation is necessary. Let $t=1 / \sum_{i=1}^{m} v_{i} x_{i o}$, $\mu_{r}=t u_{r},(r=1,2, \ldots, s)$ and $\omega_{i}=t v_{i},(i=1,2, \ldots, m)$. Then, the model becomes

$$
\begin{aligned}
\text { Maximize } & \sum_{r=1}^{s} \mu_{r} y_{r o}=\theta_{o} \\
\text { subject to } & \sum_{i=1}^{m} \omega_{i} x_{i o}=1 \\
& \sum_{r=1}^{s} \mu_{r} y_{r j}-\sum_{i=1}^{m} \omega_{i} x_{i j} \leq 0, j=1,2, \ldots, n \\
& \mu_{\mathrm{r}}, \omega_{i} \geq 0, r=1,2, \ldots, s ; i=1,2, \ldots, m .
\end{aligned}
$$

The CCR model is based on the assumption that the return to scale is constant. However, in some circumstances, the return to scale changes. Banker et al. (1984) ${ }^{[47]}$ extended the CCR model to account for variable returns to scale, which became known 
as the BCC (Banker, Charnes, and Cooper, 1984) model:

$$
\begin{aligned}
\text { Maximize } & \sum_{r=1}^{s} \mu_{r} y_{r o}-u_{o} \\
\text { subject to } & \sum_{i=1}^{m} \omega_{i} x_{i o}=1 \\
& \sum_{r=1}^{s} \mu_{r} y_{r j}-\sum_{i=1}^{m} \omega_{i} x_{i j}-u_{o} \leq 0, j=1,2, \ldots, n \\
& \mu_{\mathrm{r}}, \omega_{i} \geq 0, r=1,2, \ldots, s ; i=1,2, \ldots, m .
\end{aligned}
$$

\subsection{Tobit regression}

Once we calculated the efficiency scores, a censored variable was formed and we used the Tobit regression to further examine determinant efficiency factors. The Tobit regression was first proposed by Tobit ${ }^{[48]}$ in 1958 and the standard form is as follows:

$$
\begin{aligned}
& y^{*}=\alpha+\beta x_{i}+\mu_{i} \\
& y^{*}=y_{i} \text { if } y^{*}>0 \\
& y^{*}=0 \text { if } y^{*} \leq 0 .
\end{aligned}
$$

where $y^{*}$ is the potential dependent variable, $\alpha$ is the constant term, $x_{i}$ is the impact factor, $\beta$ is the coefficient vector, and $\mu_{i}$ is the error term. The Tobit regression follows a normal distribution. In this study, we generally used the following form (Carlucci, 2018 and Chaouk, 2020) ${ }^{[49-50]}$ :

$$
y^{*}=\beta x_{i}+\mu_{i},
$$

For this study's purpose, the Tobit regression equations were established as follows:

$$
\begin{aligned}
& E F F_{j}^{1}=\alpha_{1} x_{1 j}+\alpha_{2} x_{2 j}+\alpha_{3} x_{3 j}+\alpha_{4} x_{4 j}+\alpha_{5} x_{5 j}+\alpha_{6} x_{6 j}+\mu_{j} \\
& E F F_{t}^{2}=\beta_{1} x_{1 t}+\beta_{2} x_{2 t}+\beta_{3} x_{3 t}+\beta_{4} x_{4 t}+\beta_{5} x_{5 t}+\beta_{6} x_{6 t}+\varepsilon_{t} .
\end{aligned}
$$

where $E F F_{j}^{1}$ represents the 2017 Chinese provincial efficiency scores,$\quad j(j=1, \ldots, 31)$ represents the 31 provinces, $E F F_{t}^{2}$ represents China's national efficiency scores, $t(t=1, \ldots, 11)$ represents each year from 2007 to $2017, x_{i j}, x_{i t}$ represents the impact 
factors, and $\alpha_{i}, \beta_{i}$ represents the regression coefficient.

\subsection{Theil index}

In 1967, Thiel proposed the Theil index ${ }^{[51]}$, which is a measure of inequality based on the information theory. It can be written as

$$
T=\frac{1}{n} \sum_{i=1}^{n} \frac{y_{i}}{\bar{y}} \log \left(\frac{y_{i}}{\bar{y}}\right)
$$

where $T$ is the Thiel index, $y_{i}$ represents the actual value of the observed indicator in region $i$, and $\bar{y}$ represents the average value of all regional observations. The smaller the Thiel index, the smaller the distribution difference will be.

The results of the network DEA were obtained using DEA-SOLVER Pro5.0 software. The results of the Tobit regression analysis were obtained using EViews 10 software. The results of the Theil index were obtained using R x64 3.6.1 software.

\section{Empirical Study}

\subsection{Data Sources and Description}

According this paper's purpose, the variables were divided into three aspects: input variables (medical service), output variables (residents' health status), and independent variables (HRH).

\subsubsection{Input and Output Variables}

The variable selection was guided by previous research and data availability. We focused on analyzing the efficiency of the provincial and national dimensions, respectively. Three variables were taken into account: "outpatient visits", "inpatient visits", and "surgical procedures", which were used as medical services for residents' health status. "Surgical procedures" had an apparent correlation with physicians and registered nurses and was used as a control variable. According to health indicators proposed in the "healthy China 2030" plan, which included "life expectancy", "infant 
mortality", "maternal mortality", and "mortality in children younger than 5 years", we selected the above four variables to apply to resident health status.

However, because we still lack provincial data regarding "infant mortality" and "mortality in children younger than 5 years", these two variables were replaced in the provincial dimension with "perinatal mortality" and "prevalence in low weight children younger than 5 years", respectively. Moreover, variables in the DEA models were non-negative ${ }^{[52]}$ except for "life expectancy". This paper applied a monotone decreasing transformation by taking the reciprocal of the other three undesirable variables and multiplying the reciprocal by 100 or 10 , which allowed the output variables to be positive.

\subsubsection{Independent Variables}

In the Tobit regression analysis, HRH were used as independent variables and impacted the output efficiency of residents' health status. There are six major categories of $\mathrm{HRH}$ in Chinese medical institutions: licensed (assistant) doctors, registered nurses, pharmacists, technicians, village doctors, and others (novitiate HRH). Considering the data dimension of the regression model, this paper instead used the proportion of each HRH category. Table 2 presents variable selection.

Table 2. Model variables.

\begin{tabular}{ccc}
\hline Input: medical service $(\mathrm{I})$ & Output: residents' health status $(\mathrm{O})$ & Independent variables $(x)$ \\
\hline Outpatient visits $\left(\mathrm{I}_{1}\right)$ & Infant mortality $\left(\mathrm{O}_{1}\right)$ & Licensed (assistant) doctors $\left(x_{1}\right)$ \\
\hline Inpatient visits $\left(\mathrm{I}_{2}\right)$ & Mortality in children younger than & Registered nurses $\left(x_{2}\right)$ \\
Surgical procedures & 5 years $\left(\mathrm{O}_{2}\right)$ & \\
$\left(\right.$ control variable) $\left(\mathrm{I}_{3}\right)$ & Maternal mortality $\left(\mathrm{O}_{3}\right)$ & Pharmacists $\left(x_{3}\right)$ \\
& & Technicians $\left(x_{4}\right)$ \\
& & Vife expectancy $\left(\mathrm{O}_{4}\right)$ \\
& & Otlage doctors $\left(x_{5}\right)$ \\
\end{tabular}


In this study, the data were acquired from the China health statistics yearbook (2008-2018), which was published in the Chinese language by the Chinese central government. In case of a statistical divergence, the China health statistics yearbook in 2018 shall prevail.

\subsubsection{Correlation analysis of Input and Output Variables}

Table 3 shows a correlation analysis of input and output variables in the national dimension in China from 2007 to 2017. Obviously, there were strong positive correlations between the variables. The correlation coefficient ranged from 0.873 to 0.994, demonstrating that medical services had a positive impact on residents' health status.

Table 3. Correlation analysis of input and output variables in the national dimension.

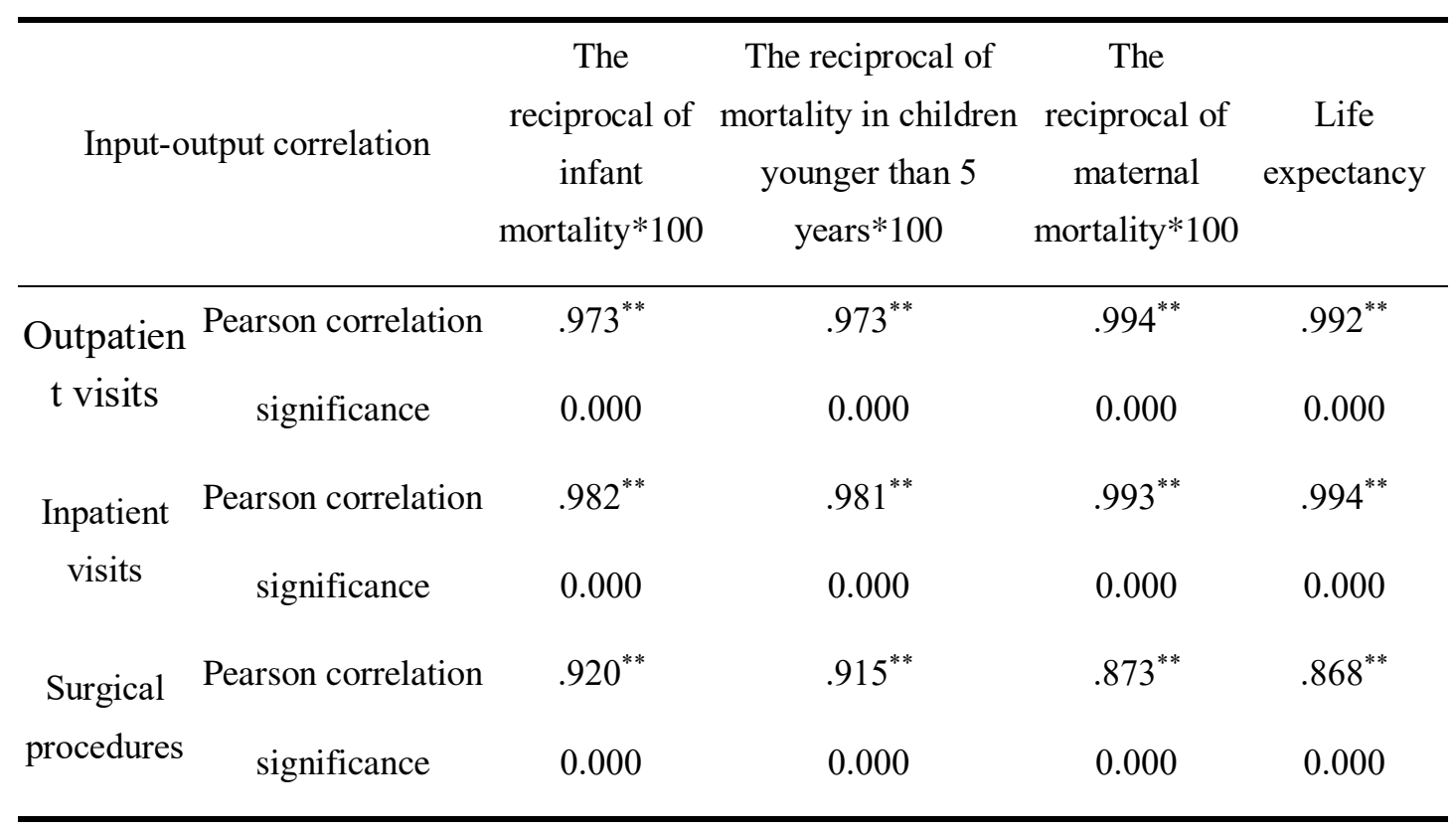

Note: $* * * * *$, and $*$ denote significance at the 1,5 , and $10 \%$ statistical level, respectively.

Table 4 shows a correlation analysis of input and output variables in the provincial dimension in China (31 provinces) from 2017. Only "perinatal mortality" was associated with "outpatient visits" and "surgical procedures". There was almost no significant correlation between the other variables. 
Table 4 Correlation analysis of output and input variables in the provincial dimension

\begin{tabular}{|c|c|c|c|c|c|}
\hline \multicolumn{2}{|c|}{ Input-output correlation } & \multirow{2}{*}{$\begin{array}{c}\text { The } \\
\text { reciprocal of } \\
\text { perinatal } \\
\text { mortality*100 } \\
.427 *\end{array}$} & \multirow{2}{*}{$\begin{array}{c}\text { The reciprocal of } \\
\text { prevalence in low } \\
\text { weight children } \\
\text { younger than } 5 \\
\text { years*10 } \\
-0.051\end{array}$} & \multirow{2}{*}{$\begin{array}{c}\text { The reciprocal } \\
\text { of maternal } \\
\text { mortality*100 } \\
0.172\end{array}$} & \multirow{2}{*}{$\begin{array}{c}\begin{array}{c}\text { Life } \\
\text { expectancy }\end{array} \\
0.338\end{array}$} \\
\hline Outpatient & Pearson correlation & & & & \\
\hline visits & significance & 0.017 & 0.786 & 0.355 & 0.063 \\
\hline Inpatient & Pearson correlation & 0.336 & -0.276 & -0.038 & 0.131 \\
\hline visits & significance & 0.064 & 0.132 & 0.839 & 0.483 \\
\hline Surgical & Pearson correlation & $.406^{*}$ & -0.059 & 0.187 & 0.301 \\
\hline procedures & significance & 0.024 & 0.752 & 0.315 & 0.099 \\
\hline
\end{tabular}

Note: * denote significance at the $10 \%$ statistical level.

\subsection{Results of DEA}

\subsubsection{The Efficiency Scores of Each Province}

In the provincial dimension, we used data from 31 provinces in China (2017). Each province was treated as a DMU. Figure 1 shows the visual representation of the efficiency for each province, revealing that the efficiency scores with and without the variable of "surgical procedures" presented no significant difference. 


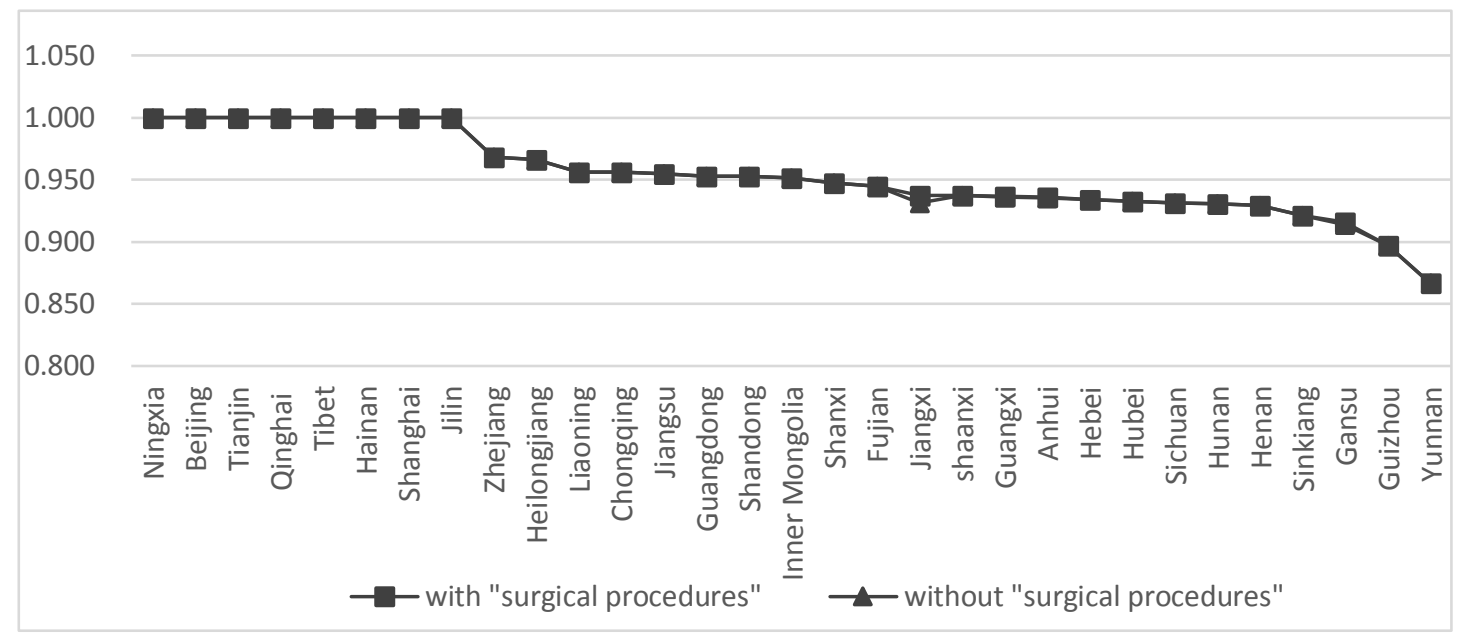

Figure 1. The efficiency scores of each province in 2017.

As can be seen, there were only eight fully efficient provinces: Ningxia, Beijing, Tianjin, Qinghai, Tibet, Hainan, Shanghai, and Jilin. Conversely, Sinkiang, Gansu, Guizhou, and Yunnan had low efficiency. The results proved that even if some provinces (i.e., Ningxia, Qinghai, Tibet, and Hainan) were economically underdeveloped, they were still efficiently outputted. On the contrary, we found that economically developed provinces (i.e., Zhejiang, Jiangsu, and Guangdong) were inefficient.

\subsubsection{The Efficiency Scores of the Whole Country}

In the national dimension, we used time series data from 2007 to 2017. Each year was treated as a DMU. There is a rule of thumb that the number of units should be at least twice the number of inputs and outputs in order to preserve discriminatory power [53-56]. In this article, the factor analysis reduced the dimension of residents' health status variables.

$$
y=0.994 * o_{1}+0.996 * o_{2}+0.992 * o_{3}+0.975 * o_{4}
$$

where $y$ represents the residents' health status and is the only output variable, $o_{1}$ is the positive change of infant mortality, $o_{2}$ is the positive change of mortality in children younger than 5 years, $o_{3}$ is the positive change of maternal mortality, and 
$o_{4}$ is life expectancy. Input variables were the same for the provincial analysis. We also separated samples with and without the "surgical procedures" variable.

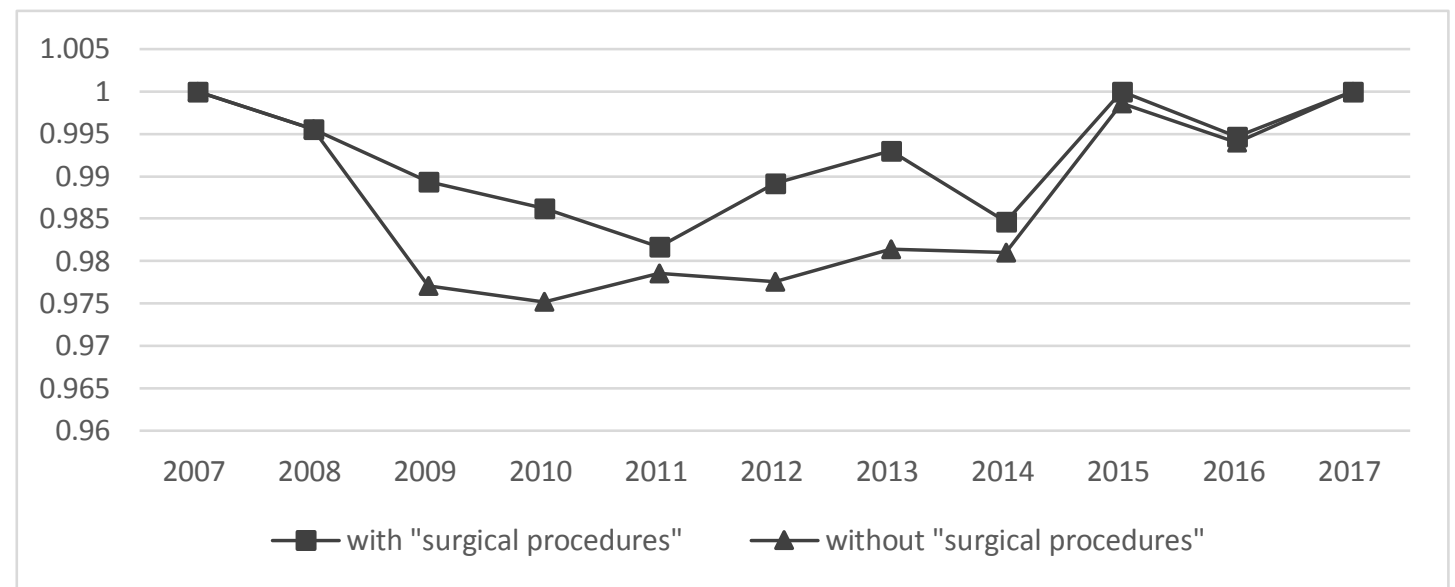

Figure 2. Trend of national efficiency in China from 2007 to 2017.

Figure 2 presents the national output efficiency of residents' health status in China from 2007 to 2017 . We found that there were slightly lower efficiency scores during the 2009-2014 period and a significant difference when "surgical procedures" were taken into account.

\subsection{Results of Tobit Regression Analysis}

We considered HRH allocation as a possible influential factor on efficiency. Efficiency scores were used as dependent variables and the proportions of each type of $\operatorname{HRH}\left(x_{1}, x_{2}, x_{3}, x_{4}, x_{5}, x_{6}\right)$ were used as independent variables.

\subsubsection{Determinants of Provincial Efficiency in China}

Table 5 shows the estimation results of the Tobit regression analysis from the provincial dimension. The impact factors in both models (with and without "surgical procedures") were almost the same. Except for technicians $\left(x_{4}\right)$, every other HRH category in the provincial dimension was statistically significant and positive $(\mathrm{p}<0.05)$. When analyzing the "with surgical procedures" model, the largest correlation 
coefficient was for pharmacists $\left(x_{3}, 3.529\right)$, followed by licensed (assistant) doctors ( $x_{1}$, $1.154)$, village doctors $\left(x_{5}, 0.886\right)$, others $\left(x_{6}, 0.667\right)$, and registered nurses $\left(x_{2}, 0.416\right)$. Therefore, we concluded that almost all kinds of HRH have a generally significant impact on efficiency. More importantly, pharmacists $\left(x_{3}\right)$ have the greatest influence; they were found to be three times more influential than licensed (assistant) doctors. This highlights the importance of improving the provincial output efficiency of residents' health status.

Table 5. Determinants of provincial efficiency.

\begin{tabular}{ccccc}
\hline \multirow{2}{*}{ Variable } & \multicolumn{2}{c}{ With "surgical procedures" } & \multicolumn{2}{c}{ Without "surgical procedures" } \\
& Coefficient1 & Prob.1 & Coefficient2 & Prob.2 \\
\hline $\mathrm{X}_{1}$ & 1.154 & 0.000 & 1.168 & 0.000 \\
$\mathrm{X}_{2}$ & 0.416 & 0.047 & 0.419 & 0.049 \\
$\mathrm{X}_{3}$ & 3.529 & 0.001 & 3.498 & 0.002 \\
$\mathrm{X}_{4}$ & 2.078 & 0.220 & 1.957 & 0.255 \\
$\mathrm{X}_{5}$ & 0.886 & 0.000 & 0.880 & 0.000 \\
$\mathrm{X}_{6}$ & 0.667 & 0.030 & 0.690 & 0.027 \\
\hline
\end{tabular}

\subsubsection{Determinants of the National Efficiency in China}

Table 6 shows the estimation results of the Tobit regression analysis for the national dimension. It can be seen that the two models were affected by different kinds of HRH. We accept that the "with surgical procedures" model was directly correlated with doctors and nurses. Moreover, licensed (assistant) doctors $\left(x_{1}, 2.224\right)$, registered nurses $\left(x_{2}, 1.044\right)$, and village doctors $\left(x_{5}, 0.728\right)$ all had significant and positive effects on the efficiency at the $1 \%$ statistical level. However, in the "without surgical procedures" model, the effect factors changed to registered nurses $\left(x_{2}, 1.095\right)$ and pharmacists $\left(x_{3}, 11.028\right)$, indicating that pharmacists affect efficiency 11 times more than registered nurses. 
Table 6. Determinants of national efficiency

\begin{tabular}{ccccc}
\hline \multirow{2}{*}{ Variable } & \multicolumn{2}{c}{ With "surgical procedures" } & \multicolumn{2}{c}{ Without "surgical procedures" } \\
& Coefficient1 & Prob.1 & Coefficient2 & Prob.2 \\
\hline $\mathrm{X}_{1}$ & 2.224 & 0.000 & 0.437 & 0.531 \\
$\mathrm{X}_{2}$ & 1.044 & 0.000 & 1.095 & 0.000 \\
$\mathrm{X}_{3}$ & 3.422 & 0.411 & 11.028 & 0.017 \\
$\mathrm{X}_{4}$ & -8.107 & 0.115 & -1.744 & 0.764 \\
$\mathrm{X}_{5}$ & 0.728 & 0.005 & 0.244 & 0.411 \\
$\mathrm{X}_{6}$ & 0.139 & 0.851 & -0.095 & 0.909 \\
\hline
\end{tabular}

When comparing the above four models, it can be seen that HRH had different impacts on the output efficiency of residents' health status. It is important to note, however, that pharmacists played a critical role. Thus, this analysis can provide insightful implications for hospital and health policy makers.

\subsection{Results of Theil Index}

For further discussion, we used the Theil index to measure inequality trends of HRH distribution among provinces from 2007 to 2017. Based on our above conclusions, this paper analyzed practicing (assistant) physicians, registered nurses, pharmacists, and technicians. Figure 3 shows a daunting equity challenge for HRH distribution in China. Although the Theil index decreased, the most severe inequality was seen for pharmacists. The Theil index for technicians revealed a similar decreasing trend, but it was the minimum compared to the other three HRH categories since 2011. It is also worth noting that the inequality distribution of practicing (assistant) physicians and registered nurses remarkably increased. In conclusion, if inequalities were a problem, our data could support the above research conclusions. 


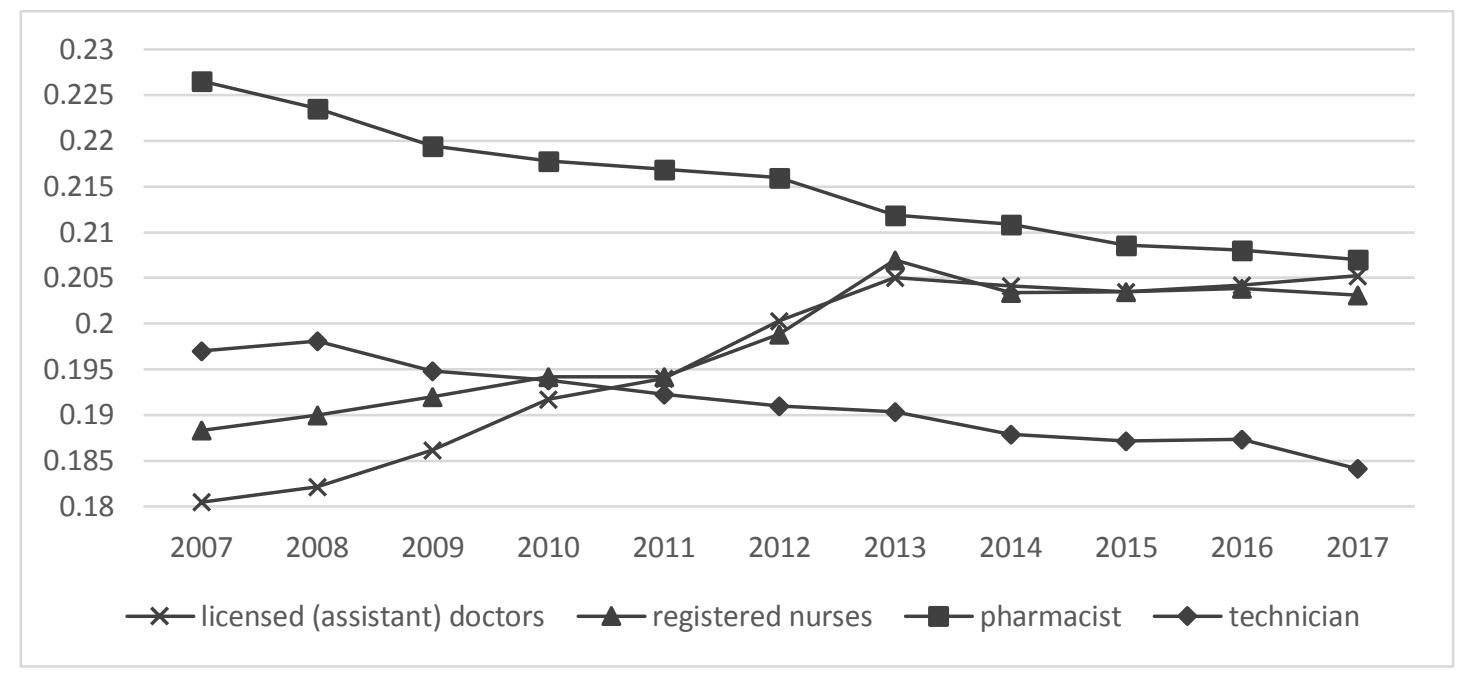

Figure 3. Theil indexes of human resources for health (HRH) distribution in China from 2007 2017.

Source: China health statistics yearbook 2008-2018

\section{Discussion}

Considering the above analysis, it is clear that the role of Chinese pharmacists merits further discussion. With the improvement of health care awareness, there is asymmetry between the demand for drug therapy and the lack of clinical pharmacists. In addition, Chinese clinical pharmacists do not have prescription rights and physicians are typically valued more highly than pharmacists, which often leads to unreasonable drug use. Over the past decade, the Chinese government has increased their investment of medical resources and the number of HRH have increased. However, after an increase in the total number of personnel, the proportion of pharmacists has declined. According to the China health statistics yearbook, in 2017 China had 45,298 pharmacists in medical institutions, which accounts for $5 \%$ of the total number of HRH. Since the abolition of drug price additions, hospital pharmacy windows are full of people and pharmacists spend a lot of time dispensing and supplying medications instead of conducting clinical pharmacy work in hospitals.

\section{Conclusions and Policy Recommendations}

\subsection{Conclusions}


This paper considered the impact of HRH on the output efficiency of residents' health status. In the provincial dimension, there was no significant difference between the two models, proving that almost all kinds of HRH (except for technicians) had a generally significant impact on efficiency. In the national dimension, licensed (assistant) doctors, registered nurses, and village doctors had significantly positive effects on efficiency in the "with surgical procedures" mode. Meanwhile, the effect factors changed to registered nurses and pharmacists in the "without surgical procedures" model. More importantly, pharmacists showed the greatest influence on both the provincial and national output efficiency of residents' health status.

\subsection{Policy Recommendations}

Optimizing the allocation of HRH should be a top priority for healthcare systems and the government should adopt a long-term perspective. First, there should be an increased focus on professional training clinical pharmacists and promoting the implementation of prescription rights for pharmacists so that they can provide convenient medical services, reduce irrational drug use, and monitor patients who need long-term medication. Secondly, the health sector should pay more attention to increasing the number and quality of $\mathrm{HRH}$ in order to narrow the gap across provinces. Moreover, additional policies should be established to attract more health workers to work in primary hospitals or rural areas. Finally, more research should be carried out on the layout of $\mathrm{HRH}$, such as discerning the most effective proportion between different types of HRH or allocating HRH among different medical institutions. The ultimate goal is to improve the overall efficiency of medical services and residents' health status.

\section{Abbreviations}

HRH: Human resources for health ; 
DEA: Data envelopment analysis;

DMUs: Decision making units;

CCR: Charnes, Cooper, and Rhodes;

BCC: Banker, Charnes, and Cooper, 1984

\section{Acknowledgements}

The support of colleagues and staff in Northeastern University, China Institute for Reform and Development and the First Affiliated Hospital of Hainan Medical University are equally appreciated.

\section{Funding}

This study was supported by the Hainan Federation of Social Science Circles, grant number HNSK(WT)18-139.

\section{Availability of data and materials}

The data were acquired from the China health statistics yearbook $(2008-2018)$, which was published in the Chinese language by the Chinese central government. Please contact author for data requests.

\section{Authors' contributions}

JJC analyzed the data and wrote the manuscript. XMK is the supervisor of the project and sequentially aligned the parts of the research paper. LHZ was involved in the data collection and participated in the manuscript writing and revision. All authors have read and agreed to the published version of the manuscript. 


\section{Author' information}

${ }^{1}$ Jingjing Cheng(1986-), Female, doctoral candidate, engaged in the research on the allocation of human resources for health.

${ }^{2}$ Xianming Kuang(1978-), Male, Researcher, $\mathrm{PhD}$ supervisor, engaged in the research on the theory and policy of China's reform.

${ }^{3}$ Linghuang Zeng(1989-), Male, master degree, engaged in the research on the management of human resources for health .

\section{Ethics approval and consent to participate}

Not applicable.

\section{Consent for publication}

Not applicable.

\section{Competing interests}

The authors declare that they have no competing interests

\section{References}

${ }^{[1]}$ Chen R, Zhao Y, Du J, et al. Health workforce equity in urban community health service of China[J]. PloS one, 2014, 9(12).

${ }^{[2]}$ Yu Q, Yin W, Huang D, et al. Trend and equity of general practitioners' allocation in China 
Based on the Data from 2012-2017[J]. 2020.

${ }^{[3]}$ Yang L, Yin Y, Wang H. Is the health workforce distribution in Beijing, China perfectly equitable?[J]. Ethiopian Journal of Health Development, 2019, 33(1).

${ }^{[4]}$ World Health Organization. Global strategy on human resources for health: workforce 2030. Geneva: WHO; 2015. p. 25

${ }^{[5]}$ Maresova, P.; Prochazka, M.; Barakovic, S.; Baraković Husić, J.; Kuca, K. A Shortage in the Number of Nurses-A Case Study from a Selected Region in the Czech Republic and International Context. Healthcare 2020, 8, 152.

${ }^{[6]}$ Pagaiya N, Phanthunane P, Bamrung A, et al. Forecasting imbalances of human resources for health in the Thailand health service system: application of a health demand method[J]. Human resources for health, 2019, 17(1): 4.

${ }^{[7]}$ Saw Y M, Than T M, Thaung Y, et al. Myanmar's human resources for health: current situation and its challenges[J]. Heliyon, 2019, 5(3): e01390.

${ }^{[8]}$ Armocida B, Formenti B, Ussai S, et al. The Italian health system and the COVID-19 challenge[J]. The Lancet Public Health, 2020.

${ }^{[9]}$ Narasimhan V, Brown H, Pablos-Mendez A, et al. Responding to the global human resources crisis[J]. The Lancet, 2004, 363(9419): 1469-1472.

${ }^{[10]}$ Fraher E P, Pittman P, Frogner B K, et al. Ensuring and Sustaining a Pandemic Workforce[J]. New England Journal of Medicine, 2020.

${ }^{[11]}$ Grill J, Bryant C, Markel K, et al. A study of time saved by emergency medicine physicians through working with clinical pharmacists in the emergency department[J]. The American journal of emergency medicine, 2019, 37(9): 1720-1722.

${ }^{[12]}$ Jacobi J. Clinical pharmacists: practitioners who are essential members of your clinical care team[J]. Revista Médica Clínica Las Condes, 2016, 27(5): 571-577.

${ }^{[13]}$ Dalton K, Byrne S. Role of the pharmacist in reducing healthcare costs: current insights[J]. Integrated pharmacy research \& practice, 2017, 6: 37.

${ }^{[14]}$ Ung C O L. Community pharmacist in public health emergencies: quick to action against the coronavirus 2019-nCoV outbreak[J]. Research in Social and Administrative Pharmacy, 2020.

${ }^{[15]}$ Cutler D M. Walking the tightrope on Medicare reform[J]. Journal of Economic Perspectives, 2000, 14(2): 45-56.

${ }^{[16]}$ Arrow K J.Uncertainty and the welfare economics of medical care[J]. The American economic review,1963,(53):941.

${ }^{[17]} \mathrm{Hu}$ R, Zou H, Shen C. Health Care System Reform in China: Issues, Challenges and Options[M]//China Economics and Management Academy, Central University of Finance and Economics. 2011.

${ }^{[18]}$ Wagstaff A, Van Doorslaer E. Equity in the finance of health care: some international comparisons[J]. Journal of health economics, 1992, 11(4): 361-387.

${ }^{[19]}$ Tang S, Meng Q, Chen L, et al. Tackling the challenges to health equity in China[J]. The Lancet, 2008, 372(9648): 1493-1501.

${ }^{[20]}$ Meng Q, Mills A, Wang L, et al. What can we learn from China's health system reform?[J]. bmj, 2019, 365: 12349. 
${ }^{[21]} \mathrm{Fu}$ X, Li J, Sun N, et al. Evaluation of the Concentration Index of the Fairness of Health Resources Allocation in China[C]//2nd International Conference on Social Science, Public Health and Education (SSPHE 2018). Atlantis Press, 2019.

${ }^{[22]}$ Chowdhury H, Zelenyuk V, Laporte A, et al. Analysis of productivity, efficiency and technological changes in hospital services in Ontario: How does case-mix matter?[J]. International Journal of Production Economics, 2014, 150: 74-82.

${ }^{[23]}$ Tomblin Murphy G, MacKenzie A, Alder R, et al. Pilot-testing an applied competency-based approach to health human resources planning[J]. Health policy and planning, 2013, 28(7): 739749.

${ }^{\text {[24] }}$ Sun J, Luo H. Evaluation on equality and efficiency of health resources allocation and health services utilization in China[J]. International journal for equity in health, 2017, 16(1): 127.

${ }^{[25]}$ Ding J, Hu X, Zhang X, et al. Equity and efficiency of medical service systems at the provincial level of China's mainland: a comparative study from 2009 to 2014[J]. BMC public health, 2018, 18(1): 214.

${ }^{\text {[26] }} \mathrm{Hu}$ H H, Qi Q, Yang C H. Evaluation of China's regional hospital efficiency: DEA approach with undesirable output[J]. Journal of the Operational Research Society, 2012, 63(6): 715-725.

${ }^{[27]} \mathrm{Hu} \mathrm{H} \mathrm{H}$, Qi Q, Yang C H. Analysis of hospital technical efficiency in China: Effect of health insurance reform[J]. China Economic Review, 2012, 23(4): 865-877.

${ }^{[28]}$ Cheng Z, Cai M, Tao H, et al. Efficiency and productivity measurement of rural township hospitals in China: a bootstrapping data envelopment analysis[J]. BMJ open, 2016, 6(11): e011911.

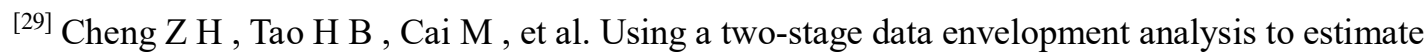
the efficiency of county hospitals in China: a panel data study[J]. The Lancet, 2015, 386(8):S64.

${ }^{[30]}$ Gong G, Chen Y, Gao H, et al. Has the Efficiency of China's Healthcare System Improved after Healthcare Reform? A Network Data Envelopment Analysis and Tobit Regression Approach[J]. International Journal of Environmental Research and Public Health, 2019, 16(23): 4847.

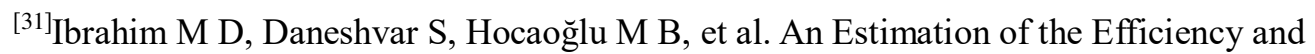
Productivity of Healthcare Systems in Sub-Saharan Africa: Health-Centred Millennium Development Goal-Based Evidence[J]. Social Indicators Research, 2019, 143(1): 371-389.

${ }^{[32]}$ Kounetas K, Papathanassopoulos F. How efficient are Greek hospitals? A case study using a double bootstrap DEA approach[J]. The European Journal of Health Economics, 2013, 14(6): 979-994.

${ }^{[33]}$ Nedelea I C, Fannin J M. Analyzing cost efficiency of critical access hospitals[J]. Journal of Policy Modeling, 2013, 35(1): 183-195.

${ }^{[34]}$ Chowdhury H, Zelenyuk V. Performance of hospital services in Ontario: DEA with truncated regression approach[J]. Omega, 2016, 63: 111-122.

${ }^{[35]}$ Kakemam E, Dargahi H. The Health Sector Evolution Plan and the Technical Efficiency of Public Hospitals in Iran[J]. Iranian journal of public health, 2019, 48(9): 1681.

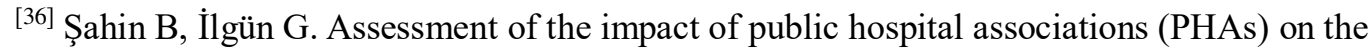
efficiency of hospitals under the ministry of health in Turkey with data envelopment analysis[J]. Health care management science, 2019, 22(3): 437-446.

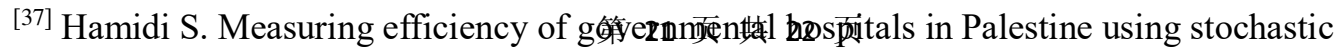


frontier analysis[J]. Cost Effectiveness and Resource Allocation, 2016, 14(1): 3.

${ }^{[38]}$ Lee K, Chun K, Lee J. Reforming the hospital service structure to improve efficiency: Urban hospital specialization[J]. Health policy, 2008, 87(1): 41-49.

${ }^{[39]}$ Afonso A, St. Aubyn M. Assessing health efficiency across countries with a two-step and bootstrap analysis[J]. Applied Economics Letters, 2011, 18(15): 1427-1430.

${ }^{[40]}$ Chen S,Wu Y, Yao C, et al.Analysis of operation performance of general hospitals in Shenzhen, China: a super-efficiency data envelopment analysis[J]. The Lancet,2016,388.

${ }^{[41]}$ Asandului L, Roman M, Fatulescu P. The efficiency of healthcare systems in Europe: A data envelopment analysis approach[J]. Procedia Economics and Finance, 2014, 10: 261-268.

${ }^{[42]}$ Yang C C. Measuring health indicators and allocating health resources: a DEA-based approach[J]. Health care management science, 2017, 20(3): 365-378.

${ }^{[43]} \mathrm{Ng}$ Y C. The productive efficiency of Chinese hospitals[J]. China Economic Review, 2011, 22(3): 428-439

${ }^{[44]}$ Kontodimopoulos N, Nanos P, Niakas D. Balancing efficiency of health services and equity of access in remote areas in Greece[J]. Health policy, 2006, 76(1): 49-57.

${ }^{[45]}$ Charnes A, Cooper W W, Rhodes E. Measuring the efficiency of decision making units[J]. European journal of operational research, 1978, 2(6): 429-444.

${ }^{[46]}$ Charnes A, Cooper W W. Programming with linear fractional functionals[J]. Naval Research logistics quarterly, 1962, 9(3-4): 181-186.

${ }^{[47]}$ Banker R D, Charnes A, Cooper W W. Some models for estimating technical and scale inefficiencies in data envelopment analysis[J]. Management science, 1984, 30(9): 1078-1092.

${ }^{[48]}$ Tobin J. Estimation of relationships for limited dependent variables[J]. Econometrica: journal of the Econometric Society, 1958: 24-36.

${ }^{[49]}$ Carlucci F, Cirà A, Coccorese P. Measuring and explaining airport efficiency and sustainability: Evidence from Italy[J]. Sustainability, 2018, 10(2): 400.

${ }^{[50]}$ Chaouk M, Pagliari R, Moxon R. The impact of national macro-environment exogenous variables on airport efficiency[J]. Journal of Air Transport Management, 2020, 82: 101740.

${ }^{[51]}$ Theil H. Economics and information theory[R]. 1967.

${ }^{[52]}$ Sarkis J. Preparing your data for DEA[M]/Modeling data irregularities and structural complexities in data envelopment analysis. Springer, Boston, MA, 2007: 305-320.

${ }^{[53]}$ Golany B, Roll Y. An application procedure for DEA[J]. Omega, 1989, 17(3): 237-250.

${ }^{[54]}$ Boussofiane A, Dyson R G, Thanassoulis E. Applied data envelopment analysis[J]. European journal of operational research, 1991, 52(1): 1-15.

${ }^{[55]}$ Ueda T, Hoshiai Y. Application of principal component analysis for parsimonious summarization of DEA inputs and/or outputs[J]. Journal of the Operations Research Society of Japan, 1997, 40(4): 466-478.

${ }^{[56]}$ Adler N, Golany B. Evaluation of deregulated airline networks using data envelopment analysis combined with principal component analysis with an application to Western Europe[J]. European Journal of Operational Research, 2001, 132(2): 260-273. 
Figures

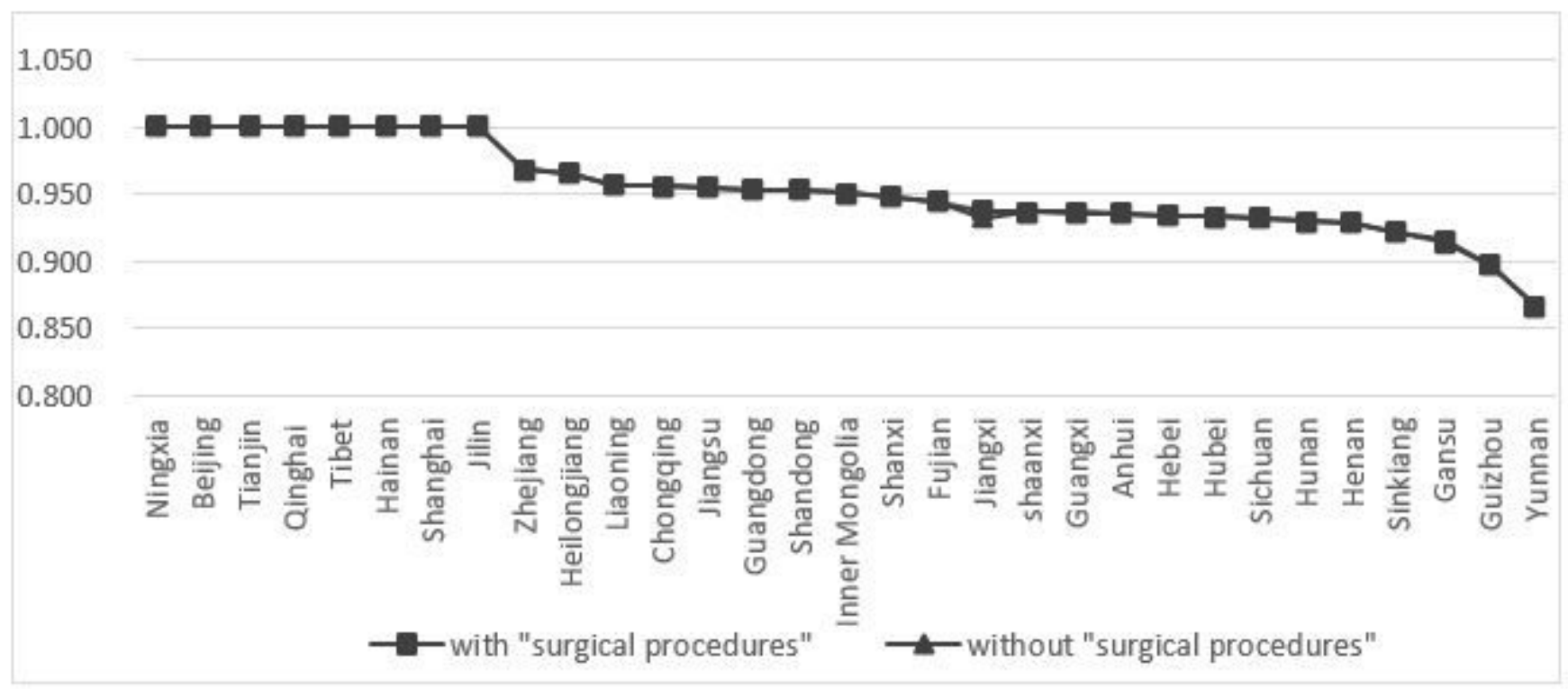

\section{Figure 1}

The efficiency scores of each province in 2017.

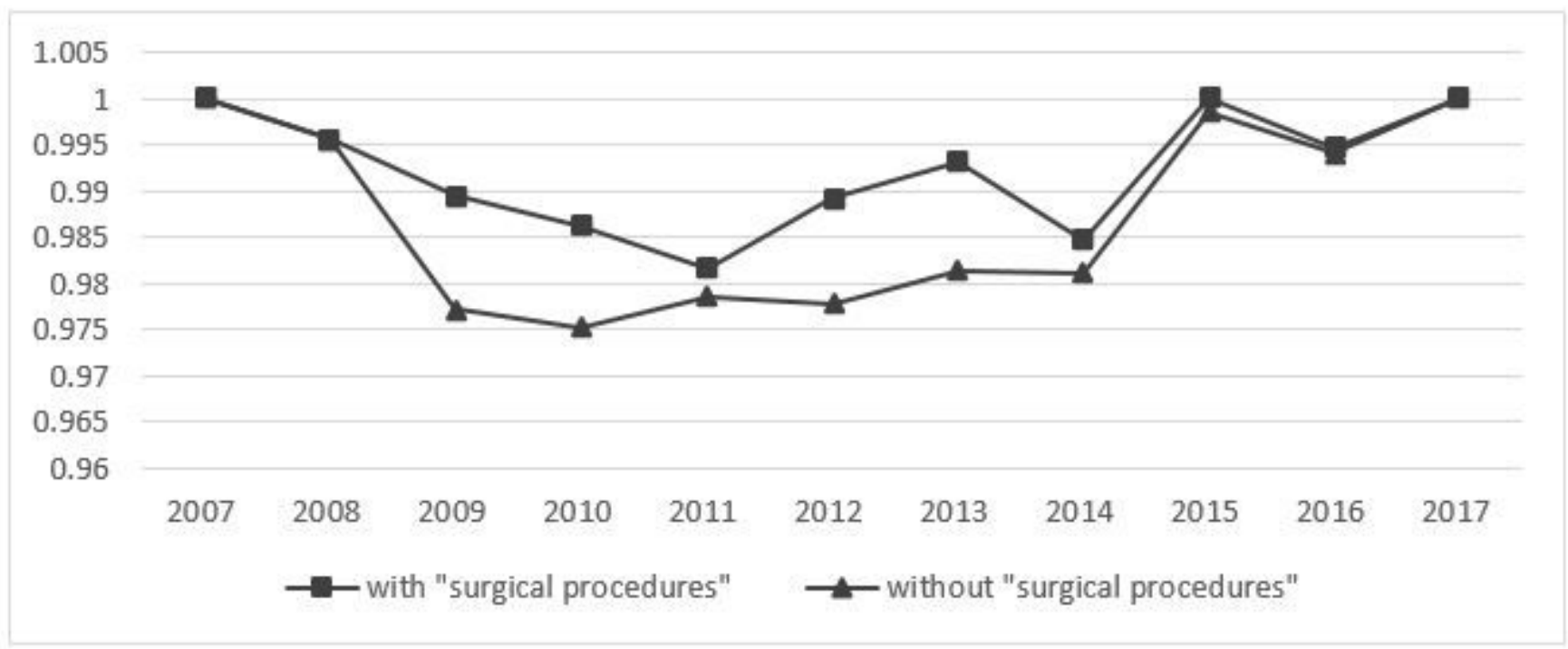

Figure 2

Trend of national efficiency in China from 2007 to 2017. 


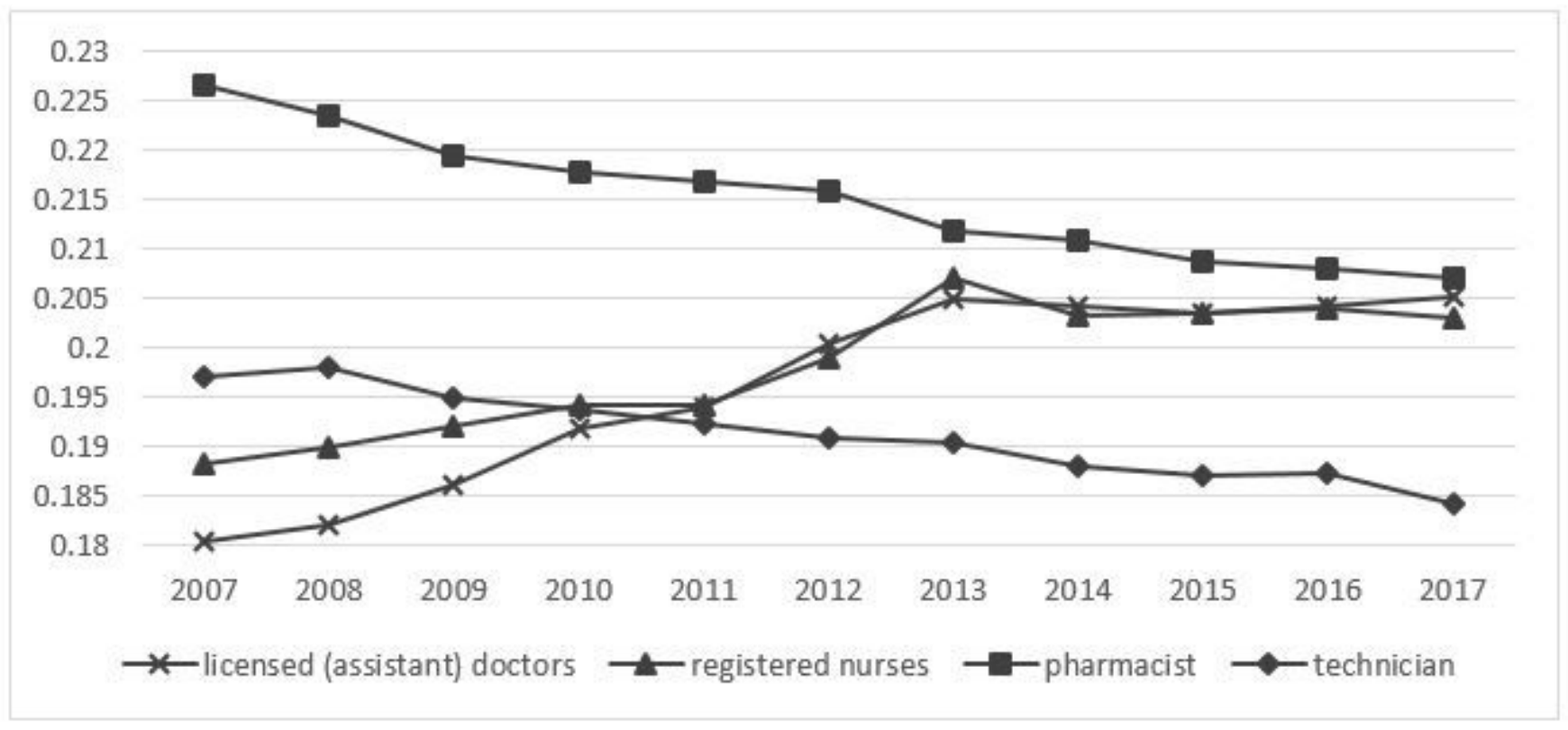

\section{Figure 3}

Theil indexes of human resources for health $(\mathrm{HRH})$ distribution in China from 2007 - 2017. Source: China health statistics yearbook 2008-2018 